\title{
PERANCANGAN APLIKASI CATALOG WISATA DI SUMATERA UTARA MENGGUNAKAN ALGORITMA RABIN-KARP
}

\author{
Ade Ambarwati br ginting, Dito Putro Utomo \\ Program Studi Teknik Informatika STMIK Budi Darma, Medan, Indonesia \\ Email: Adeambarwati91@gmail.com,
}

\begin{abstract}
Abstrak
String matching adalah proses pencarian semua kemunculan query atau disebut dengan pattern ke dalam string atau text.String matching merupakan pencocokan string atau kata yang digunakan pada permasalahan untuk menemukan pola susunan karakter string didalam sebuah kalimat. String matching merupakan suatu teknik dalam menentukan keakuratan dari suatu pola teks yang diberikan. Objek wisata di Sumatera Utara adalah salah satu destinasi wisata terpopuler di sumatera utara yaitu Danau Toba karena indahnya pemandangan banyak orang luar atau mancanegara juga mengunjungi wisata tersebut . kurangnya informasi tentang objek wisata suamatera utara maka penulis merancang catalog wisata untuk membantu masyarakat dalam mencari objek wisata terbaru yang ada di sumatera utara seperti wisata alam, wisata sejarah, wisata Religi dan masih banyak bisa bisa kita kunjungi wisata yang ada di sekitar sumatera utara. Algoritma Rabin-Karp merupakan fungsi hashing untuk menemukan pattern di dalam string. Dalam pencarian catalog wisata dengan algoritma Rabin-Karp sangat cocok digunakan karena algoritma Rabin-Krap digunakan untuk mencari suatu kata terdapat dalam pencarian wisata. Sehingga dalam tahap pengujian membutuhkan software eclipse dalam perancangan pembuatan catalog wisata.
\end{abstract}

Kata Kunci: String Matching, Objek Wisata, Catalog Wisata, Algoritma Rabin-Karp, Eclipse

\section{Abstract}

String matching is the process of finding all occurrences of a query or called a pattern into a string or text. String matching is a string or word matching that is used in the problem to find the pattern of string characters in a sentence. String matching is a technique in determining the accuracy of a given text pattern. Attractions in North Sumatra is one of the most popular tourist destinations in North Sumatra, Lake Toba because of the beautiful scenery of many outsiders or foreigners also visit the tour. Lack of information about North Sumatra tourism objects, the authors designed a tourism catalog to help the community in finding the latest attractions in North Sumatra such as natural attractions, historical tourism, religious tourism and many more can we visit the attractions around North Sumatra. The Rabin-Karp algorithm is a hashing function to find patterns in a string. In searching a travel catalog with the Rabin-Karp algorithm, it is very suitable to use because the Rabin-Krap algorithm is used to search for a word contained in a travel search. So that the testing phase requires eclipse software in the design of making travel catalogs.

Keywords: String Matching, Attraction, Tourism Catalog, Rabin-Karp Algorithm, Eclipse

\section{PENDAHULUAN}

Sumatera Utara merupakan salah satu provinsi yang memiliki objek wisata yang sangat indah, baik wisata alam, sejarah maupun budaya. Objek wisata yang sangat terkenal di Sumatera Utara adalah Danau Toba, banyak mancanegara menikmati keindahan alam dimana salah satu wisata yang sangat indah. Sumatera Utara banyak objek wisata yang di bisa di kunjungi kita, tetapi sebagian orang sulit untuk mencari lokasi wisata yang di kunjungi, maka dibuat katalog wisata untuk memudahkan wisata dari luar kota atau mancanegara mengunjungi objek wisata di Sumatera Utara.Objek wisata sangat baik di kelola oleh pemerintah, mulai dari bermacam tempat wisata keluarga, adanya taman-taman kota yang yang dibuat dengan indah untuk bisa menarik perhatian wisata untuk mengunjungi nya. objek wisata di bangun oleh pemerintah dengan tujuan dapat dijadikan tempat rekreasi warga kota untuk sekedar jalan-jalan, atau saling berinteraksi dengan sesama warga kota lain untuk membuat daya tarik bagi wisatawan untuk melakukan rekreasi bersama keluarga.

Objek wisata di Sumatera Utara yang terkenal dikalangan umum ataupun luar Sumatera Utara adalah Danau Toba, padahal masih banyak objek wisatalain yang terdapat di Sumatera Utara khususnya di setiap daerah kota/kabupaten seperti Air Terjun Bukit Gibeon di kabupaten Simalungun, Kawah Putih Tinggi Raja di kabupaten Simalungun, Penangkaran Gajah Tangkahan di Kabupaten Langkat, Observasi Orang Utan Di Bahorok Bukit Lawang di Kabupaten Langkat, serta masih banyak lainnya. Kesenjangan itu dikarenakan kurangnya berita, informasi dan juga referensi terhadap objek wisata tersebut ataupun objek wisata disetiap kabupaten/kota. Hal itu menjadikanbanyak orang bingung untuk mengetahui objek wisata apa saja yang terdapat pada kabupaten/kota yang dikunjungi. Sehingga perlu di buat suatu referensi tentang catalog wisata supaya dapat dengan mudah mencari referensi objek wisata padakabupaten/kota di Sumatera Utara.Kesenjangan yang muncul adalah masyarakat masih banyak yang belum mengetahui bahwa di Sumatera Utara terdapat banyak wisata yang dapat di kunjungi, baik wisata alam, wisata taman kota,wisata sejarah dan wisata budaya.

Untuk mempermudah pencarian pada referensi catalog objek wisata dibutuhkan suatu cara dengan menggunakan algoritma string matching. String matching merupakan pencocokan string atau kata yang digunakan pada permasalahan untuk menemukan pola susunan karakter string didalam sebuah kalimat. String matching merupakan suatu teknik dalam menentukan keakuratan dari suatu pola teks yang diberikan. Ada banyak algoritma string matching salah satunya adalah algoritma Rabin-Karp.Algoritma Rabin Karp menggunakan fungsi hashing untuk menemukan pattern didalam string teks[1]. 
Sehingga, dalam hal pencarian catalog wisata algoritma Rabin-Karp sangat cocok digunakan karena algoritma Rabin-Krap digunakan untuk mencari suatu kata terdapat dalam pencarian wisata. Perangkat teknologi informasi yang berkembang di zaman sekarang adalah smartphone. Oleh karena itu, menyebabkansmartphone sekarang semakin canggih dan menjadi sarana didalam membantu masyarakat untuk pencarian objek wisata.

Pada penelitian sebelumnya yang dilakukan oleh Herriyance dengan judul "Analisis Algoritma Rabin-Karp Pada Kamus Berbasis Android” mengatakan bahwasannya algoritma Rabin-Karp berhasil diterapkan pada aplikasi kamus umum dan waktu untuk melakukan pencariaan lebih cepat.

\section{LANDASAN TEORI}

\section{String Matching}

String Matching adalah proses pencarian semua kemunculan query yang selanjutnya disebut pattern ke dalam string yang lebih panjang (teks). Pattern di lambangkan dengan $\mathrm{x}=\mathrm{x}[0 . . \mathrm{m}-1]$ dan panjangnya adalah $\mathrm{m}$. Teks dilambangkan dengan $\mathrm{y}=\mathrm{y}[0 . . \mathrm{n}-1]$ dan panjangnya adalah $\mathrm{n}$. Kedua string terdiri dari sekumpulan karakter yang disebut alfabet yang dilambangkan dengan $\sum$ dan mempunyai ukuran $\sigma$. String matching dibagi menjadi dua, yakni exact matching dan heuristic atau statistical matching[2].Algoritma string matching adalah suatu metode yang digunakan untuk menemukan suatu keakuratan atau hasil dari satu atau beberapa pola teks yang diberikan. String matching merupakan pokok bahasan yang penting dalam ilmu komputer karena teks merupakan merupakan bentuk utama dari pertukaran informasi antar manusia, misalnya pada literatur, karya ilmiah, halaman web, dan sebagainya.Dalam algoritma string matching, teks diasumsikan berada di dalam memory, sehingga bila kita mencari string di dalam sebuah teks, maka semua isi teks perlu dibaca terlebih dahulu kemudian disimpan didalam memory. String matching fokus pada pencarian satu, atau lebih umum, semua kehadiran sebuah kata (pattern) dalam sebuah teks[3].

Pencocokan pola merupakan teknik yang bisa digunakan untuk menentukan apakah suatu string sesuai dengan pola yang telah dispesifikasi sebelumnya. Pola dapat dibuat dengan menggunakan kombinasi karakter biasa. Selama pencocokan pola karakter biasa harus cocok dengan apa yang dispesifikasikan pada string[4].

\section{Exact Matching}

Exact matching digunakan untuk menemukan pattern yang berasal dari satu teks. Contoh pencarian exact matching adalah pencarian kata " pelajar" dalam kalimat "saya seorang pelajar" atau " saya seorang siswa". Sistem akan memberikan hasil bahwa kalimat pertama mengandung kata "pelajar" sedangkan kalimat kedua tidak, meskipun kenyataannya pelajar dan siswa adalah kata yang bersinonim[2].

2. Heuristic Matching

Heuristic matching adalah teknik yang digunakan untuk menghubungkan dua data terpisah ketika exact matching tidak mampu mengatasi karena ada pembatasan pada data yang tersedia. Heuristic matching dapat dilakukan denganperhitungan distance antara pattern dengan teks. Euzenat (2007) menuliskan beberapa contoh heuristic matching berdasarkan distance adalah stringbased technique yang meliputi string equality, edit distance, tokenbased distance, dan path comparissan. Dalam buku ini hanya akan dijelaskan n-gram similarity yang termasuk kategori string equality.

$\mathrm{N}$-gram similarity sering digunakan untuk membandingkan beberapa string. Metode ini menghitung sejumlah $\mathrm{n}$ gram bersama seperti serangkaian di antara string. Sebagai contoh bigram untuk string article adalah "ar", "rt", "ti", "ic", "cl", "le", sedangkan untuk trigram adalah "art", "rti”, "tic", "icl”, "cle". Perhitungan kemiripan dua string dapat diukur menggunakan jaccard Coefficient, yaitu:

Jaccard Coefficient $($ pattern,text $)=\frac{\mid \text { pattern } n \text { text } \mid}{\mid \text { pattern } v \text { text } \mid}$

Berikut ini contoh bagaimana menghitung kemiripan dari duabuah string menggunakan $n$-gram similarity. Terdapat dua buah string, yaitu artikel dan arikel, maka nilai kemiripan berdasarkan bigram dan trigram similarity adalah :

Artikel $=$ ar, rt, ti, ik, ke, el

Artikel $=$ ar, ri, ik, ke,el

$\operatorname{Sim}($ Artikel,Arikel $)=\frac{4}{7}=0,57$

Jika menggunakan trigram kemiripannya adalah

Artikel $=$ art, rti, tik, ike, kel

Artikel $=$ ari, rik, ike, $\mathrm{kel}$

Sim (Artikel,Arikel $)=\frac{2}{7}=0,29$

Sedangkan jika dihitung kemiripan antara jurnal dan artikel, maka kemiripannya adalah 0 padahal menurut makna, kedua kata ini mirip. Perhitungan n-gram similarty cocok digunakan untuk mengantisipasi kesalahan pengetikan query yang diberikan pengguna.Exact dan heuristic string matching memiliki kelemahan dalam menemukan kata yang memiliki kemiripan makna tetapi berbeda tulisan. Beberapa konten terkait dengan query yang diberikan juga tidak dapat terambil. Kekurangan yang terakhir ini dapat diatasi dengan menggunakan pencarian metadata[2]. 


\section{Algoritma Rabin-karp}

Algoritma ini merupakan menggunakan metode hash dalam mencari suatu kata. Teori ini jarang digunakan untuk mencari kata tunggal, namun cukup penting dan sangat efektif untukpencarian pattern. Dimana fungsi hash menyimpan bentuk string dalam bentuk lain yaitu enumerasi sehingga suatu string tertentu akan memiliki nilai enumerasinya yang unik. tentang perancangan dan implementasi sistem penilaian jawaban esai otomatis menggunakan algoritma Rabin-Karp, dimana untuk mencarai nilai hash digunakan persamaan (1):

$$
\begin{aligned}
& \mathrm{H}=\mathrm{C} 1 * \mathrm{~B}(\mathrm{~m}-1)+\mathrm{C} 2 * \mathrm{~B}(\mathrm{~m}-2)+\ldots+\mathrm{C}(\mathrm{m}-1) * \mathrm{Bm}+\mathrm{Cm} \\
& \text { Dimana: } \\
& \mathrm{H}=\text { Nilai Hash } \\
& \mathrm{C}=\text { ASCII karakter } \\
& \mathrm{B}=\text { Basis (bilangan prima) } \\
& \mathrm{m}=\text { Banyak karakter (panjang karakter) }
\end{aligned}
$$

\section{ANALISA DAN PEMBAHASAN}

\subsection{Analisa Catalog Wisata}

Sumatera Utara adalah salah satu objek wisata terbanyak yang bisa kita kunjungi seperti wisata Alam, wisata alam banyak objek wisata yang bisa di kunjungi seperti, danau Toba dimana danau toba salah satu wisata yang sangat banyak di kunjungi masyarakat karena indahnya pemandangan. wisata selanjuntnya adalah wisata sejarah yang bisa kita kunjungi di Sumatera utara adalah museum Negeri, gallery rahmat dan masih banyak lagi, dan wisata yang bisa dikunjungi lagi adalah wisata Religi yang ada di sumatera utara adalah istana maimun, velangkani dan sebagainya.

Pencarian objek wisata menggunakan catalog wisata dimana pengguna harus mengetahui nama Kabupaten/ kota, nama Wisata, tentang dan sebagainya dalam memudahkan pengguna menggunakan catalog wisata. dalam penyusunan katalog wisata kita membutuhkan suatu Database yang digunakan penulis adalah SQLite. Dimana SQLitemenggabungkan data dariberbagai tabel untuk menghasilkanlaporan danrangkumandata. Dimana penulis membutuhkan suatu algoritmaUntuk mempermudah pencarian pada referensi catalog wisata dalam mencari objek wisata yang dibutuhkan suatu cara dengan menggunakan algoritma string matching. String matching merupakan pencocokan string atau kata yang digunakan pada permasalahan untuk menemukan pola susunan karakter string didalam sebuah kalimat.

Pada umumnya hampir semua kalangan masyarakat menggunakan smartphone yang berbasis android dengan adanya aplikasi catalog yang akan di rancang oleh penulis adalah untuk memudahkan dalam pencarian objek wisata dimana pun dan kapan pun kita membutuhkan saat ingin berpergian suatu tempat atau objek wisata.

Pencarian suatu lokasi objek wisata di sumatera utara menggunakan Algoritma Rabin-Karp. dimana membutuhkan aplikasi catalog wisata yang akan dirancang oleh penulis dalam membantu masyarakat dalam melakukan pencarian karakter dan text berdasarkan pattern yang ditentukan. Algoritma Rabin-Karp pada pattern yang dicari sudah ditemukan, proses pencarian akan terus dilakukan jika panjang karakter pada text memungkinkan.

Pada proses pencarian objek wisata menggunakan catalog, maka untuk menentukan terlebih dahulu pattern atau kata kunci yang akan dicari. Kemudian algortima akan melakukan proses pencocokan pada tiap karakter text untuk menemukan pattern yang dicari. Setelah selesai, akan muncul hasil ditemukan atau tidaknya pattern yang dicari. Jika ditemukan, kemungkinan akan ada beberapa pilihan nama wisata yang cocok dengan pattern atau kata kunci yang dicari. Kemudian memilih salah satu Kota/ Kabupaten maka akan muncul berbagai pilihan objek wisata yang akan di kunjungi.

\subsection{Penerapan Algortima Rabin-Karp}

Pada contoh kasus ini penulis akan melakukan pencarian objek wisata berdasarkan nama kabupaten/kota, misalnya pencarian dengan teks DELI SERDANG yang menggunakan kata "SERDANG" sebagai pattern-nya maka proses pencarian adalah sebagai berikut.

Contoh Kasus:

Text : DELI SERDANG

Pattern : SERDANG

1. Langkah Pertama :

Text yang digunakan pada contoh kasus ini adalah "DELI SERDANG", pada langkah pertama menghapuskan spasi atau tanda baca.

Text : DELISERDANG

2. Langkah Kedua:

Langkah selanjutnya adalah parsing k-gram, dimana pada proses ini katadipecah menjadi potongan-potongan dimana setiap potongan mengandung karaktersebanyak K. Berikut ini adalah contoh proses parsing K-gram $\mathrm{K}=7$ : 


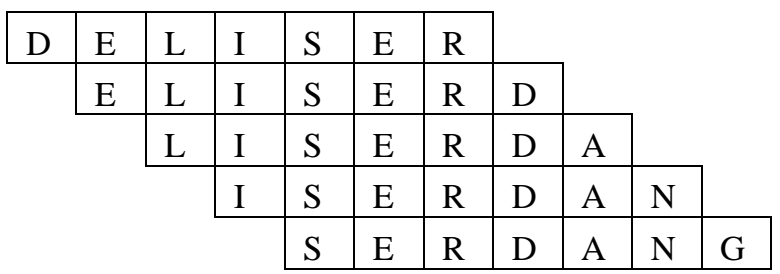

3. Langkah ketiga :

Langkah selanjutnya menghitung nilai Hash dari K-gram yang sudah dibagi dengan menggunakan rumus :

$\mathrm{H}=\mathrm{c} 1 * \mathrm{bk}-1+\mathrm{c} 2 * \mathrm{bk}-2+\mathrm{c} 3 * \mathrm{bk}-3+\ldots+\mathrm{ck} * \mathrm{~b} 0$

Dimana :

c : nilai ASCII karakter

b : basis (bilangan prima)

$\mathrm{k}$ : banyak karakter

$\mathrm{H}$ : Hashing

Untuk nilai B (Basis Bilangan Prima) digunakan nilai basis bilangan prima adalah 7, sehingga dapat dihitunga untuk nilai Hash setiap K-gram dan juga Pattern.

a. Pattern [SERDANG]

$$
\begin{aligned}
\mathrm{H} & =83 * 7^{7-1}+69 * 7^{7-2}+82 * 7^{7-3}+68 * 7^{7-4}+65 * 7^{7-5}+78 * 7^{7-6}+71 * 7^{7-7} \\
& =83 * 7^{6}+69 * 7^{5}+82 * 7^{4}+68 * 7^{3}+65 * 7^{2}+78 * 7^{1}+71 * 7^{0} \\
& =83 * 117649+69 * 16087+82 * 2401+68 * 343+65 * 49+78 * 7+71 \\
& =9764867+1159683+196882+23324+3185+546+71 \\
& =11148558
\end{aligned}
$$

b. K-garm 1 [DELISER]

$$
\begin{aligned}
\mathrm{H} & =68 * 7^{7-1}+69 * 7^{7-2}+76 * 7^{7-3}+73 * 7^{7-4}+83 * 7^{7-5}+69 * 7^{7-6}+82 * 7^{7-7} \\
& =68 * 7^{6}+69 * 7^{5}+76 * 7^{4}+73 * 7^{3}+83 * 7^{2}+69 * 7^{1}+82 * 7^{0} \\
& =68 * 117649+69 * 16087+76 * 2401+73 * 343+83 * 49+69 * 7+82 * 1 \\
& =8000132+1159683+182476+25039+4067+483+82 \\
& =9371962
\end{aligned}
$$

c. K-garm 2 [ELISERD]

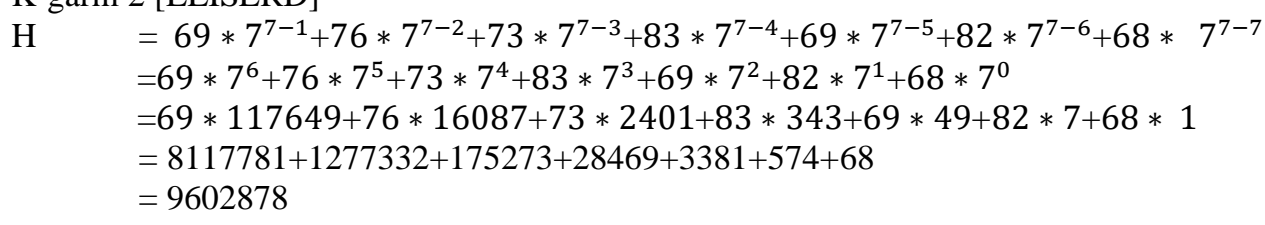

d. K-garm 3 [LISERDA]

$$
\begin{aligned}
\mathrm{H} & =76 * 7^{7-1}+73 * 7^{7-2}+83 * 7^{7-3}+69 * 7^{7-4}+82 * 7^{7-5}+68 * 7^{7-6}+65 * 7^{7-7} \\
& =76 * 7^{6}+73 * 7^{5}+83 * 7^{4}+69 * 7^{3}+82 * 7^{2}+68 * 7^{1}+65 * 7^{0} \\
& =76 * 117649+73 * 16087+83 * 2401+69 * 343+82 * 49+68 * 7+65 * 1 \\
& =8941324+1226911+199283+23667+4018+476+65 \\
& =10395744
\end{aligned}
$$

e. K-garm 4 [ISERDAN]

$$
\begin{aligned}
\mathrm{H} & =73 * 7^{7-1}+83 * 7^{7-2}+69 * 7^{7-3}+82 * 7^{7-4}+68 * 7^{7-5}+65 * 7^{7-6}+78 * 7^{7-7} \\
& =73 * 7^{6}+83 * 7^{5}+69 * 7^{4}+82 * 7^{3}+68 * 7^{2}+65 * 7^{1}+78 * 7^{0} \\
& =73 * 117649+83 * 16087+69 * 2401+82 * 343+68 * 49+65 * 7+78 * 1 \\
& =8588377+1394981+165669+28126+3332+455+78 \\
& =10181018
\end{aligned}
$$

f. K-garm 5 [SERDANG]

$$
\begin{aligned}
\mathrm{H} & =83 * 7^{7-1}+69 * 7^{7-2}+82 * 7^{7-3}+68 * 7^{7-4}+65 * 7^{7-5}+78 * 7^{7-6}+71 * 7^{7-7} \\
& =83 * 7^{6}+69 * 7^{5}+82 * 7^{4}+68 * 7^{3}+65 * 7^{2}+78 * 7^{1}+71 * 7^{0} \\
& =83 * 117649+69 * 16087+82 * 2401+68 * 343+65 * 49+78 * 7+71 * 1 \\
& =9764867+1159683+196882+23324+3185+546+71 \\
& =11148558
\end{aligned}
$$


Setelah dilakukan perhitungan nilai Hash, maka didapatkan nilai Hash K-garm Pattern 1 sampai dengan K-garm Pattern 5dengan nilai Hash [9371962, 9602878, 10395744, 10181018, 11148558].

Nilai Hash untuk K-garm teks 1 sampai dengan K-garm teks 5 [9371962, 9602878, 10395744, 10181018, 11148558]

4. Langkah keempat

Langkah selanjutnya adalah mencocokan nilai Hash K-garm Pattern dengan nilai Hash K-garm teks. Nilai Hash K-garm Pattern memiliki kesamaan dengan nilai Hash K-garm teks 1 sampai dengan nilai Hash K-garm 5 [9371962, 9602878, 10395744, 10181018, 11148558] dengan [9371962, 9602878, 10395744, 10181018, 11148558]. Kemudian mencocokan karakter string antara Pattern dengan Teks [DELI SERDANG] dengan [DELI SERDANG].

5. Langkah Kelima

Langkah terakhir adalah melakukan pengecekan similitary nilai hash pattern dengan nilai hash pada text.

Hasil Hash pada text [9371962, 9602878, 10395744, 10181018, 11148558]. Jumlah hash pada text adalah = $\sum$ HAsli5

Hasil Hash pada pattern [9371962, 9602878, 10395744, 10181018, 11148558]. Jumlah hash pada pattern adalah $=\sum \mathrm{Uji5}$

Jumlah Hash yang sama dari text dan pattern adalah $=\sum$ HAslin $\sum H U j i=5$

Setelah diketahui nilai hashnya, jumlah hash pada text adalah 5, jumlah hash pada pattern adalah 5 dan hash yang sama pada text dan pattern adalah 5. Proses selanjutnya menghitung similitary yaitu tingkat kesamaan antara text dan pattern, yaitu berapa persen tingkat kesamaannya. Berikut ini adalah proses menghitung similitary dua dokumen diatas:

$$
\begin{aligned}
\text { Similitary (Text,Pattern) } & =\frac{\sum \text { Htext } \sum \text { Hpattern }}{\sum \text { Htext } \cup \text { Hpattern }} \times 100 \% \\
& =\frac{\sum \text { Htext } \sum \text { Hpattern }}{\sum \text { Htext }+\sum \text { Hpattern- }- \text { Htext } \sum \text { Hpattern }} \times 100 \% \\
& =\frac{5}{5+5-5} \times 100 \% \\
& =\frac{5}{10-5} \times 100 \% \\
& =\frac{5}{5} \times 100 \% \\
& =100 \%
\end{aligned}
$$

\section{IMPLEMENTASI}

Adapun hasil implementasi yang dibuat adlah sebagai berikut:

1. Tampilan Menu Utama

Tampilan ini merupakan halaman awal dari aplikasi, pada tampilan ini terdiri dari tiga (3) pilihan sub menu yang dapat berpindah kehalaman baru dengan memberikan action pada sub menu yang dipilih, sub menu tersebut yaitu, Pencarian nama objek wisata tentang Aplikasi, Keluar dari Aplikasi. Adapun screenshot tampilan aplikasi catalog wisata bisa dilihat pada gambar 1 . dibawah.

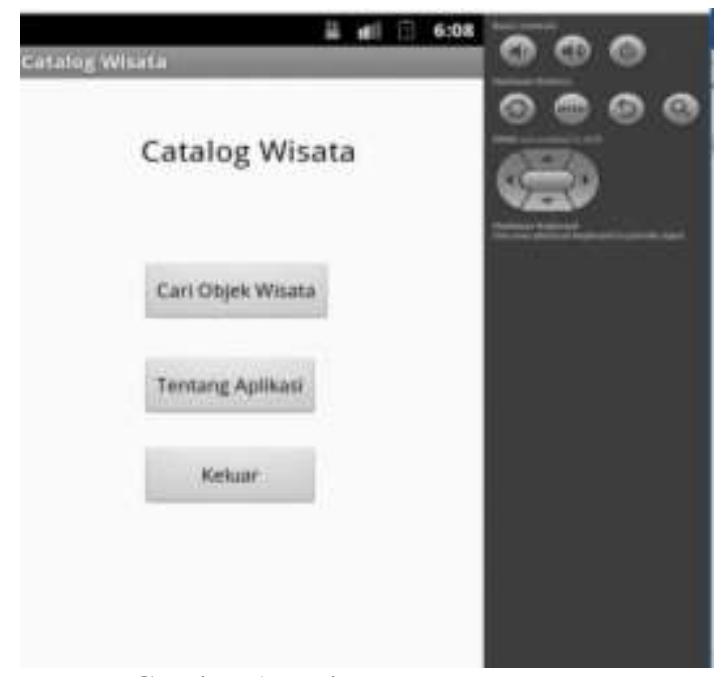

2. Tampilan Menu Pencarian

Gambar 1. Halaman Menu Utama 
Menu pencarian merupakan halaman untuk user melakukan pencarian objek wisata yang diinginkan dengan cara menginputkan nama kabupaten/ kota pada Edittextyang telah disediakan pada aplikasi. Terdapat dua objek pada halaman ini yaitu Edittext dan Listview, Edittextberfungsi sebagai tempat user menginputkan nama kabupaten yang dicari sedangkan Listview berfungsi menampilkan isi yang ada di database. Screenshot halaman menu pencarian dapat dilihat pada gambar 2. dibawah.

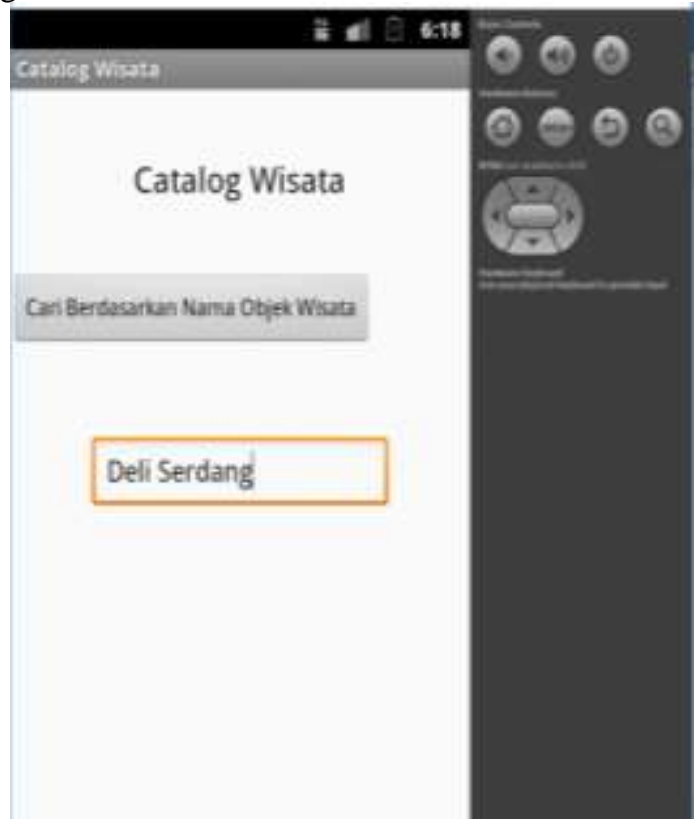

Gambar 2. Halaman Menu Pencarian

3. Tampilan Menu Hasil Pencarian

Menu hasil pencarian merupakan halaman hasil dari pencarian yang dilakukan, pada halaman ini akan memuat informasi yang dicari berupa nama kabupaten/ kota, nama objek wisata. Screenshot halaman menu hasil pencarian dapat dilihat pada gambar 4.3 dibawah.

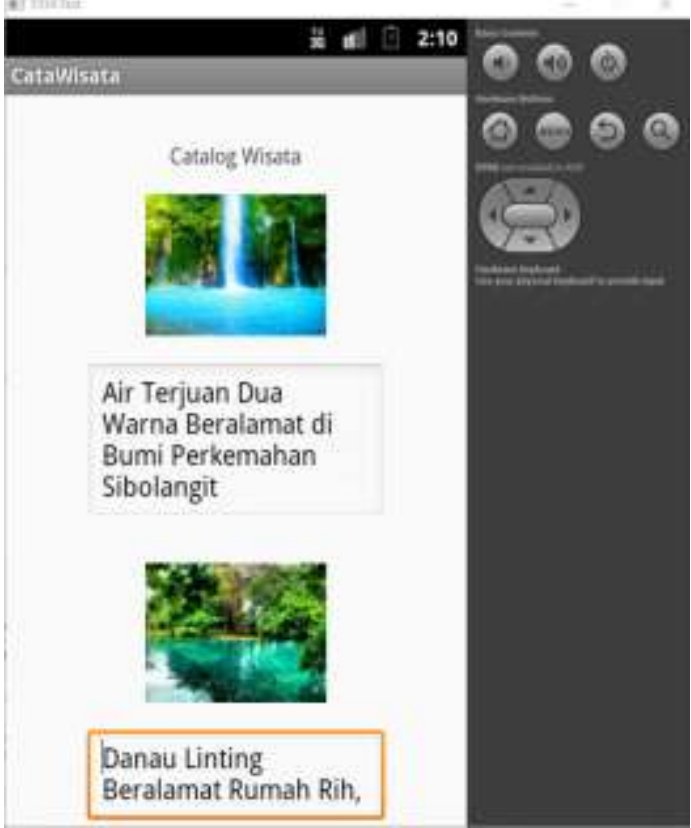

\section{KESIMPULAN}

Gambar 3. Tampilan Menu Hasil Pencarian

Berdasarkan hasil akhir pada penelitian skripsi ini penulis menarik sebuah Kesimpulan yang sekiranyadapat bermanfaat bagi pembaca, adapun kesimpulannya sebagai berikut:

1. Proses pencarian yang dilakukanapllikasi catalog wisatasangat membantu karenadapat melakukan pencarian string dengan cepat dan memberikan hasil yang tepat.

2. Algoritma Rabin-Karp yang telah diterapkan padaaplikasi catalog wisata berbasis mobile sanga tefektif dalam proses pencarian karena menghasilkan banyak informasi saat melakukan pencarian. 
3. Perancangan aplikasi Catalog wisata menghasilkan tampilan interface yang sederhanadan tampilan output pencarian mudah untuk dimengerti.

\section{REFERENCES}

[1] H. S. D. F. Herriyance, "ANALISIS ALGORITMA RABIN-KARP PADA KAMUS UMUM BERBASIS ANDROID," Jurnal Riset Sistem Informasi Dan Teknik Informatika (JURASIK), vol. 2, pp. 60-69, 2017.

[2] R. Sarno, Y. Anistyasari and F. Rahimi, "Semantic Search," in pencarian berdasarkan konten, Yogyakarta, Andi, 2012, p. 26.

[3] M. Syarif, "Implementasi Algoritma String Matching Dalam Pencarian Surah Dan Ayat Dalam Al-Quran Berbasis Web," indonesian Journal on Networking and Security, vol. 6, no. 2, p. 70, 2017.

[4] N. A. H. I. S. S. Firman Matondang, "PERANCANGAN APLIKASI TEXT EDITOR DENGAN MENERAPKAN ALGORITMA KNUTH-MORRIS-PRATT," Jurnal Riset Komputer (JURIKOM), vol. 3, no. 4, p. 16, 2016.

[5] S. S. M. \&. P. B. S. Hamza, "Sistem Koreksi Soal Essay Otomatis Dengan Menggunakan Metode Rabin Karp," Jurnal EECCIS, vol. 7, no. 2, pp. 153-158, 2013.

[6] Susanto and Mikke, Menimbang Ruang Menata Rupa, Yogyakarta: Galang press, 2004.

[7] Suyitno, Perencanaan Wisata, Yogyakarta: Kanisius, 2001.

[8] J. Enterprise, Mengenal Dasar dasar Pemograman Android, Jakarta: PT. Elex Media Komputindo, 2015.

[9] B. S. D. Oetomo, Perencanaa dan Pengembangan Sistem Informasi, Yogyakarta: CV. Andi Offset, 2002.

[10] R. A. Sukmato and M. Shalahuddin, Rekayasa Perangkat Lunak (Arsitektur Dan Berorientasi Objek), Bandung: Bandung : Informatika, 2014.

[11] A. A. S. S. M. A. S. L. S. M. Hendra Nugraha Lengkong, "Perancangan Penunjuk Rute Pada Kendaraan Pribadi Menggunakan Aplikasi Mobile GIS Berbasis Android Yang Terintegrasi Pada Google Maps," E-journal Teknik Elektro dan Komputer, p. 21, 2015. 